\title{
An efficient algae cell wall disruption methodology for recovery of intact chloroplasts from microalgae
}

\author{
Smita Patil ${ }^{1 \dagger}$, Arvind M Lali ${ }^{1,2}$, Gunjan Prakash ${ }^{1 *}$ \\ ${ }^{1}$ DBT-ICT-Centre for Energy Biosciences, Institute of Chemical Technology, Mumbai 400019, India. \\ ${ }^{2}$ Department of Chemical Engineering, Institute of Chemical Technology, Mumbai 400019, India.
}

\begin{tabular}{l}
\hline ARTICLE INFO \\
\hline Article history: \\
Received on: September 12, 2019 \\
Accepted on: January 18, 2020 \\
Available online: May 26, 2020 \\
\hline
\end{tabular}

Key words:

Microalgae, chloroplast isolation, cell wall lysis

\begin{abstract}
The microalgal cell wall breakage has been identified as complex phenomenon which is highly dependent on the nature and composition of cell wall. A detailed analysis of plastids and their function requires the breaking open of cell without any damage to cellular components. To develop a rapid and universal methodology for cell wall breakage, liquid nitrogen crushing, sonication, enzymatic lysis, and homogenization procedures were applied to various microalgal species. Homogenization-based procedure for the isolation of intact chloroplast was found to be universal for all algal species under the study. The isolated chloroplasts were subjected to chloroplast integrity analysis. The intact chloroplast exhibited a positive maximum quantum yield and $F_{\mathrm{v}} /$ $F_{\mathrm{m}}$ values ranging from 0.1 to 0.4 as measured by pulse amplitude modulation fluorometry and was found to be suitable for further downstream applications such as isolation of protein-pigment complexes involved in photosynthetic $\mathrm{O}_{2}$ evolution. The developed methodology is a quick and efficient technique for the isolation of intact chloroplasts across different genera of microalgae by employing minor changes in the base protocol as a species-specific characteristic.
\end{abstract}

\section{INTRODUCTION}

Microalgae cell wall breakage while maintaining the cellular integrity has been a gray area of research since the exact cell wall composition of most of the species is not well understood. Elaborate methodologies are available for the extraction of intracellular products, majorly lipids and carotenoids from microalgal species by various processes, such as solvent/microwave-assisted extraction, sonication, bead beating, and French press [1,2]. However, these methods are not suitable for intact cell organelle separation as they are usually applied on dry biomass and led to total cell destruction. Efficient cell breakage while preserving the intactness of chloroplast and other organelle is a prerequisite for advance understanding of various photosynthesisrelated phenomena such as interaction of various thylakoid membrane protein complexes, intra- and interorganelle protein transport, photorespiration, and

\footnotetext{
*Corresponding Author

Gunjan Prakash, DBT-ICT Centre For Energy Biosciences, Institute of Chemical Technology, N. P. Marg, Matunga, Mumbai 400019, India. E-mail: gunjaniit@gmail.com

${ }^{\dagger}$ Smita Patil is currently associated with Reliance Life Sciences, Mumbai, India
}

chlororespiration. The detailed methodology for the isolation of intact chloroplast while sustaining their physiological functions remains restricted to the model green microalgae Chlamydomonas reinhardtii, Dunaliella (including their cell wall less mutants) [3,4], and Rhodophyta, Cyanidioschyzon merolae [5]. The isolation of intact chloroplast is a critical rate limiting step for other microalgal species of interest such as Chlorella, Parachlorella, Scenedesmus, and so on, which are finding their niche applications as biofuels, chemicals, nutraceuticals, animal food and feed, pharmaceuticals, and so on [6]. Hence, there is a need of a simple, fast, and universal method for the isolation of intact chloroplast from various microalgae species. The present paper describes different methodologies used for complete cell wall removal and release of physiologically active intact chloroplasts from several microalgal species. The pros and cons of each methodology for intact chloroplast isolation were compared. Homogenization is proved to be the universal technique for species of different algal genera including Chlamydomonas, Chlorella, and Parachlorella. The isolated intact chloroplasts were further processed for the separation of major protein-pigment complexes from thylakoid membrane (structural) and pulse-amplitude modulated fluorometer (functional) integrity confirmation. The developed method has 
application in areas where cell wall breakage with intracellular organelle integrity is an absolute requirement such as antenna size determination, understanding of structure-function relationship of thylakoid membrane components, and chloroplast genome sequencing.

\section{MATERIALS AND METHODS}

\subsection{Algal Strains and Growth Conditions}

The green microalgae under the study were procured from various culture collection centers. The alga Chlamydomonas reinhardtii wild type (CC-503 cw92 mt+) and its truncated light harvesting mutants [CC-4169 tla1cw15 sr-u-2-60 mt+, CC-4472 tla2- FtsY (cw15) $\mathrm{mt}+$, and CC-4561 tla3-cpsrp43 (CW+) $\mathrm{mt}+]$ were procured from Chlamydomonas Resource Center, USA. All $C$. reinhardtii strains were grown in tris acetate phosphate (TAP) medium. The algal species Chlorella saccharophila (UTEX 247), Chlorella minutissima (UTEX 2219), and Chlorella protothecoides (UTEX 25) were procured from UTEX Culture Collection, USA. C. saccharophila and C. minutissima were cultivated in $\mathrm{MB} 3 \mathrm{~N}$, whereas $C$. protothecoides in $\mathrm{MN}$ medium. The green alga Parachlorella kessleri was procured from the Indian Institute of Technology, Chennai, and grown in Walne's medium [7]. For experiment, the algal cultures were cultivated in $2,000 \mathrm{ml}$ of polythene reactor in a specially designed environmental chamber (EC) (Fig. 1) which mimics the natural growth environment [8] with a light irradiance $\geq 1,200 \mu \mathrm{mol}$ photons $\mathrm{m}^{-2} \mathrm{~s}^{-1}$. The cells were grown until exponential growth phase $\left(\sim 10^{10}\right.$ cells $\left.\mathrm{ml}^{-1}\right)$, after which the cells were harvested by the centrifugation for 5 minutes at $10,000 \mathrm{~g}$. The cells were washed three times with 0.1 $\mathrm{M}$ potassium phosphate buffer and $\mathrm{pH} 7.4$ and resuspended in icecold grinding buffer [9] before lytic treatment.

\subsection{Cell Disruption, Purification of Intact Chloroplast, and Its Integrity Analysis}

Algal cultures were subjected to different cell disruption methods as shown in Table 1. The complete lysis of cells after cell disruption was preliminary confirmed by the formation of white

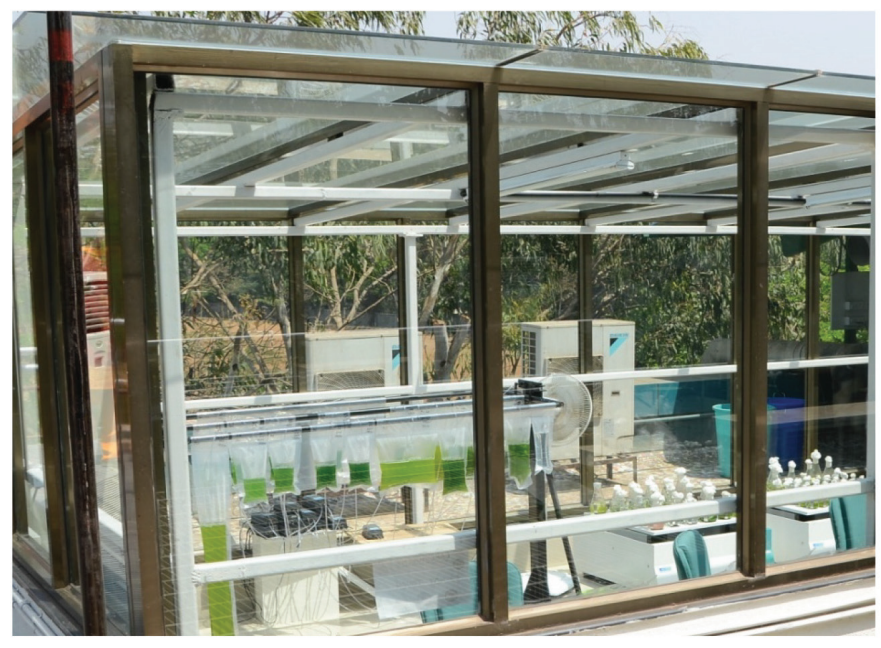

Figure 1: The EC specially designed for the growth of algae under natural light conditions. pellet suggesting the release of entire cellular content. The impact of cell disruption procedures on functional integrity of chloroplast and protein-pigment complex was preliminary determined by potassium ferricyanide photoreduction test [10]. The structural and functional integrity of chloroplasts was further confirmed by pulse amplitude modulated fluorometer (Dual-Pam-100, Heinz Walz, and Effeltrich, Germany) by the determination of chlorophyll $a$ fluorescence-based phenomena. Dark adapted values for $F_{\mathrm{m}}$ and $F_{\text {o }}$ were measured on chloroplast-rich suspension placed in the darkness for a minimum of 10 minutes so as to obtain the maximal quantum yield of photosystem II, $F_{\mathrm{v}} / F_{\mathrm{m}} ; F_{\mathrm{v}}=F_{\mathrm{m}}-F_{\mathrm{o}}[11]$. An effective quantum yield of photosystem II, Y(II) was monitored in the light adapted state of sample in the presence of red actinic light $\left(1,200 \mu \mathrm{mol}\right.$ photons $\left.\mathrm{m}^{-2} \mathrm{~s}^{-1}\right)$.

\subsection{Sucrose Density Gradient and Nondenaturing poly acryl gel electrophoresis (PAGE)}

The isolated chloroplasts were checked for their structural integrity by the separation of pigment-protein complexes. After intact chloroplast recovery, the thylakoid membranes (corresponding to $3 \mathrm{mg} / \mathrm{ml}$ of chlorophyll) were solubilized using mild denaturing agent (60 $\mu \mathrm{M}$ Octyl- $\beta$-D-glucopyranoside) [12]. The solubilized fraction was separated by centrifugation at 20,500 $\mathrm{g}$ for 10 minutes. The solubilized fraction corresponding to $1 \mathrm{mg} / \mathrm{ml}$ of chlorophyll was overlaid on $0.1-1.0 \mathrm{M}$ linear gradient of sucrose containing $60 \mu \mathrm{M}$ octyl- $\beta$-D-glucopyranoside and $0.5 \%$ Triton $\mathrm{X}$, and intact light-harvesting antenna protein (LHCII) complexes from the supernatant were recovered by sucrose density gradient ultracentrifugation at 224,000 g for 6 hours (Beckman Coulter, Ti-70 rotor). The linear gradients were achieved by using a gradient mixer with a flow rate of $2 \mathrm{ml} /$ minute. The top green band containing LHCII was collected, and a sample amounting to $10 \mu \mathrm{g} / \mu \mathrm{l}$ ( $1 \mu \mathrm{l}$ of glycerol/9 $\mu \mathrm{l}$ of sample) was separated on nondenaturing PAGE for the qualitative detection of antenna proteins. The nondenaturing PAGE was performed using 5\% stacking gel $[5 \%$ acrylamide, Tris- $\mathrm{HCl} \mathrm{pH} 6.6$ without the addition of sodium dodecyl sulphate (SDS)] and $12 \%$ resolving gel $(12 \%$ acrylamide, Tris- $\mathrm{HCl} \mathrm{pH} 8.6$, without the addition of SDS). The samples were loaded without any denaturation step to maintain the integrity of pigment-protein complexes.

\section{RESULTS AND DISCUSSION}

The outcome of different lytic treatments applied to algal species of various genera is shown in Table 1 and is elaborated as follows:

\subsection{Liquid $\mathrm{N}_{2}$ Crushing}

The application of liquid $\mathrm{N}_{2}$ for the extraction of DNA/RNA is widely reported for algal cells [13]. Liquid $\mathrm{N}_{2}$ crushing was used for the cell lysis, considering the fact that chilling temperature would also be helpful for maintaining the functional integrity of chloroplast components. Liquid $\mathrm{N}_{2}$ crushing led to very low or negligible cell wall breakage for all of the algal species under the study as indicated by a green pellet of intact cells at the bottom with slight white layer on top upon centrifugation. The top white layer can probably be due to the modest action of liquid $\mathrm{N}_{2}$ freezing on few cells releasing free chlorophylls or other pigments, which were observed in the 
Table 1: Comparison of operating conditions of different laboratory scale cell lysis techniques applied under the current study for intact chloroplast isolation from different algal species.

\begin{tabular}{|c|c|c|c|c|}
\hline Method & Operating conditions & Scale $(\mathrm{ml})$ & Processing time (min) & Visual outcome \\
\hline Liquid $\mathrm{N}_{2}$ & $0.5 \%$ slurry & 10 & 5 & Green pellet with top white layer \\
\hline Sonication & $2 \mathrm{~mm}$ probe, 30 seconds, 10 cycles & 10 & 30 & Green pellet with top white layer \\
\hline \multirow[t]{2}{*}{ Enzymatic lysis } & $1 \%$ autolysin for $C$. reinhardtii; & 1 & $360^{\mathrm{d}}$ & Green pellet ${ }^{\mathrm{b}}$ \\
\hline & $\begin{array}{l}1 \% \text { snailase }+1 \% \text { cellulase }+1 \% \text { peptidase for Chlorella } \\
\text { and Parachlorella species }\end{array}$ & & & \\
\hline Homogenization & Variable pressure and number of cycles as per species & 200 & 5 & White pellet ${ }^{\mathrm{c}}$ \\
\hline
\end{tabular}

supernatant. While suitability of this method for various algal species might be improved with multiple cycles and/ or increased crushing time with liquid $\mathrm{N}_{2}$, it was not pursued considering the chilling sensitivity of photosystems and possible photoinhibition due to prolonged liquid $\mathrm{N}_{2}$ treatment $\left(-80^{\circ} \mathrm{C}\right)$. The negative influence of chilling could be overcomed by the addition of some cryoprotectants such as glycerol, sorbitol, and so on. However, these modifications were not attempted due to limited applicability of this method in general for its small scale of operation and nonuniformity of pressure application during crushing which will be highly individual specific and prone to manual variations.

\subsection{Sonication}

Sonication has been reported for the isolation of thylakoid membrane from $C$. reinhardtii tla mutants [14] and thus was employed to analyze its suitability for the isolation of chloroplast from other microalgal species. Sonication led to incomplete cell lysis even after long exposures of up to 30 minutes (30 seconds on/ off) for Chlorella and other algae (Table 1). The procedure was not continued for longer duration as it caused the local heating of algal cells, thus negatively impacting the integrity of photosynthetic components. While sonication is a widely used technique for algal cell disruption, it mostly deals with the extraction of oils or value-added products from dry biomass $[15,1]$. The method often involves prior treatment with solvents or strong alkali for weakening of dry cell walls and hence is unsuitable for the isolation of intact chloroplasts from green algae.

\subsection{Enzymatic Lysis}

Enzymatic cell wall disruption is very efficient and welldocumented methodology for plant cell wall breakage. It is one of the main steps in the pretreatment of lignocellulosic derived cell biomass even at commercial scale [16]. However, for algal cell wall disruption, the enzymatic treatment has not been proved to be universal due to large cell wall variability among numerous algal species. In this study, incomplete cell lysis was obtained in C. reinhardtii with autolysin and other algal species even with combinations of snailase, cellulases, and peptidase (Table 1). Although the autolysin enzymes routinely used for protoplast preparation in $C$. reinhardtii, they are strain and stage specific, act on distinct strains, and recognize a specific developmental stage, which restricts its common application across different species [17]. The complex and variable cell wall composition of various algal species, particularly of Chlorella, makes it difficult to fix a single/combination of enzymes to be used for cell wall lysis, limiting the applicability of enzymatic lysis for algal cell wall removal. Further, the cell lysis is not the ultimate outcome of enzymatic treatment either, and it is possible to only form the protoplasts which would be needed to process again to isolate intact chloroplasts by combining other unit operations. Based on the own experiment and other [18] findings, it can be concluded that enzymatic treatment for cell lysis would be highly species specific in terms of the type of enzyme(s); their concoction used and would also require much longer incubation time period.

\subsection{Homogenization}

Homogenization involves the application of high-pressure energy to break cells to the smallest possible size by forcing a cell suspension through specifically engineered valve under fluid dynamic energy condition by cavitation process. Its application is well documented for downstream applications of microalgae but mostly involves complete cell destruction [19,2]. There are isolated reports of its use as a method for the isolation of antenna complex of $C$. reinhardtii chloroplast [20,9]. However, the systematic study for application of this methodology on living cells is still lacking and is yet to be explored in detail for other tough cell wall bearing algal species. We investigated the crucial specific steps of homogenization responsible for complete cell wall breakage without affecting the cellular organelle integrity (especially, for chloroplast) for C. reinhardtii and other species of commercial interest.

The initial studies with homogenization led to the formation of white pellet suggesting the complete cell wall lysis. However, complete cell lysis occurred at the expense of chloroplast destruction as confirmed by ferricyanide photoreduction due to enormous heat generation during the procedure. To overcome the heat-associated inhibition, the homogenization temperature was reduced to $4^{\circ} \mathrm{C}$. Maintaining the lower temperature during homogenization resolved the problem of heat generation, preventing the loss of structural integrity. The temperature reduction led to $>85 \%$ chloroplast intactness in all the species as opposed to only $\sim 7 \%$ without any temperature control (at their optimized pressure and number of passes). Inevitably, the rupturing of chloroplasts occurred during uncontrolled operation due to heat generation, leaving them inactive in $\mathrm{CO}_{2}$-dependent $\mathrm{O}_{2}$ evolution as indicated by decreased photoreduction. It 
is noteworthy that the higher efficiency of this process was ensured by prior cooling of homogenizer with ice-cold grinding (homogenization) buffer followed by cold inlet stream of algal culture. In a temperature-controlled environment, the lysate never reached a temperature above $4^{\circ} \mathrm{C}$ even during multiple cycles of cell lysis. In the case of Chlorella species, collection of cell lysate, in ice-cold container, kept on ice during multiple cycles further ensured the higher stability of photosynthetic membranes even after multiple passages through homogenizer. For obvious reason of cell wall composition, the homogenization protocol was modified for different species of green algae. It was noted

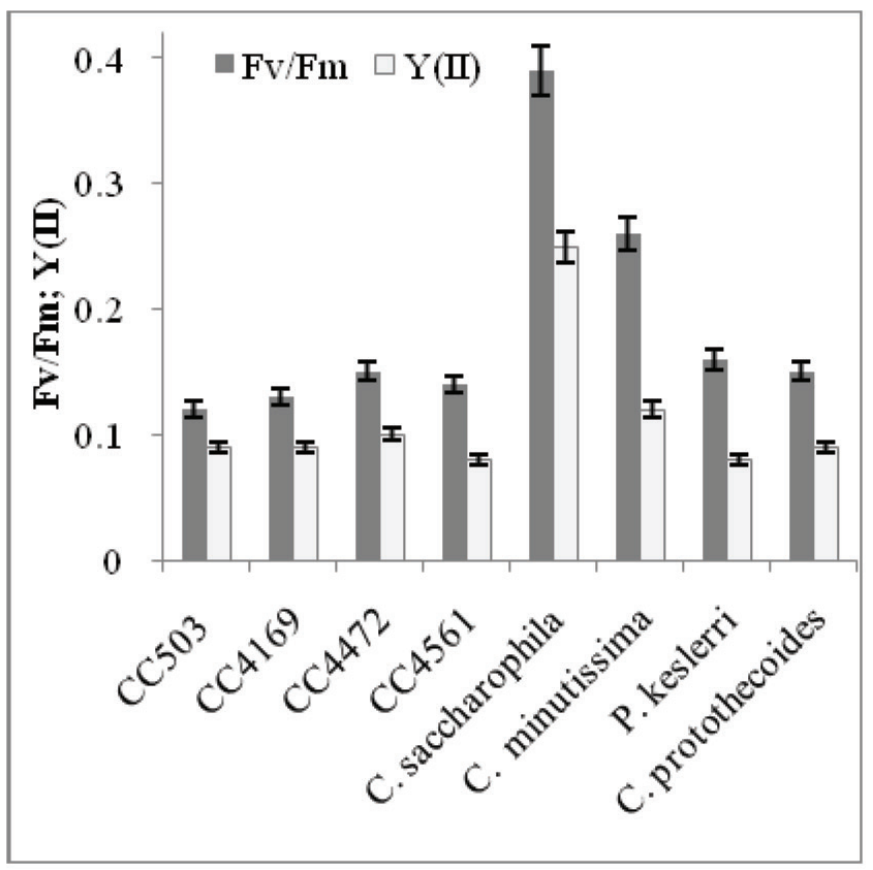

Figure 2: Chlorophyll $a$ fluorescence analysis for intact chloroplast from different green algae showing positive values of $\mathrm{Fv} / \mathrm{Fm}$ (ष) and $\mathrm{Y}$ (II) (口). that the cell wall-less C. reinhardtii (CC503) required only single cycle of homogenization at 11,600 psi compared to its cell wall bearing counterparts. Interestingly, C. saccharophila cells could only be broken only after five cycles of homogenization under as high as 17,400 psi pressure (with chloroplast integrity checked at every cycle). The other algal species responded to three cycles of homogenization with 14,500 psi indicating the great variability in cell wall composition of various algal species under the study. With temperature-controlled homogenization, the intactness of algal cells in single passage was greater $(>90 \%$, for $C$. reinhardtii) than that of cells lysed with multiple passages $(>85 \%$, for all Chlorella species). The lowered chloroplast intactness in the case of Chlorella species could be explained due to multiple homogenization passages leading to the exposure of released chloroplasts to subsequent cycles and increased susceptibility to high pressure. The integrity of PSII was assessed by probing chlorophyll $a$ fluorescence to ensure the functionality of the vital process of photosynthesis in chloroplasts isolated under these vigorous homogenization operating conditions. $F_{\mathrm{v}} / F_{\mathrm{m}}$ has routinely used parameter as an indicator of photochemical efficiency of algae. The maximal value of $F_{\mathrm{v}} / F_{\mathrm{m}}$ for algae usually ranges between 0.6 and 0.8 . The isolated chloroplasts from all the species showed a reduction in this value as well as in Y (II), an indicator of photosynthetic efficiency (Fig. 2). The values less than optimal values of $F_{\mathrm{v}} / F_{\mathrm{m}}$ and $\mathrm{Y}$ (II) for all the algal species under study denoted the lowered efficiency of photosynthesis which can be attributed to the chilling sensitivity of photosystems during the operational conditions [21]. However, the positive values of $F_{\mathrm{v}} / F_{\mathrm{m}}$ and Y(II) in all the species (Figure 2) itself are indicative of the functionality of photosystem after isolation procedure [22]. This signifies the wide application of the developed procedure for intact and functional chloroplast isolation. The intactness of isolated chloroplast and its components was further checked by solubilization of thylakoid membranes using mild denaturing agent and separation of light-harvesting antenna associated with PSII (LHCII) by sucrose density ultracentrifugation (Figure 3 ).
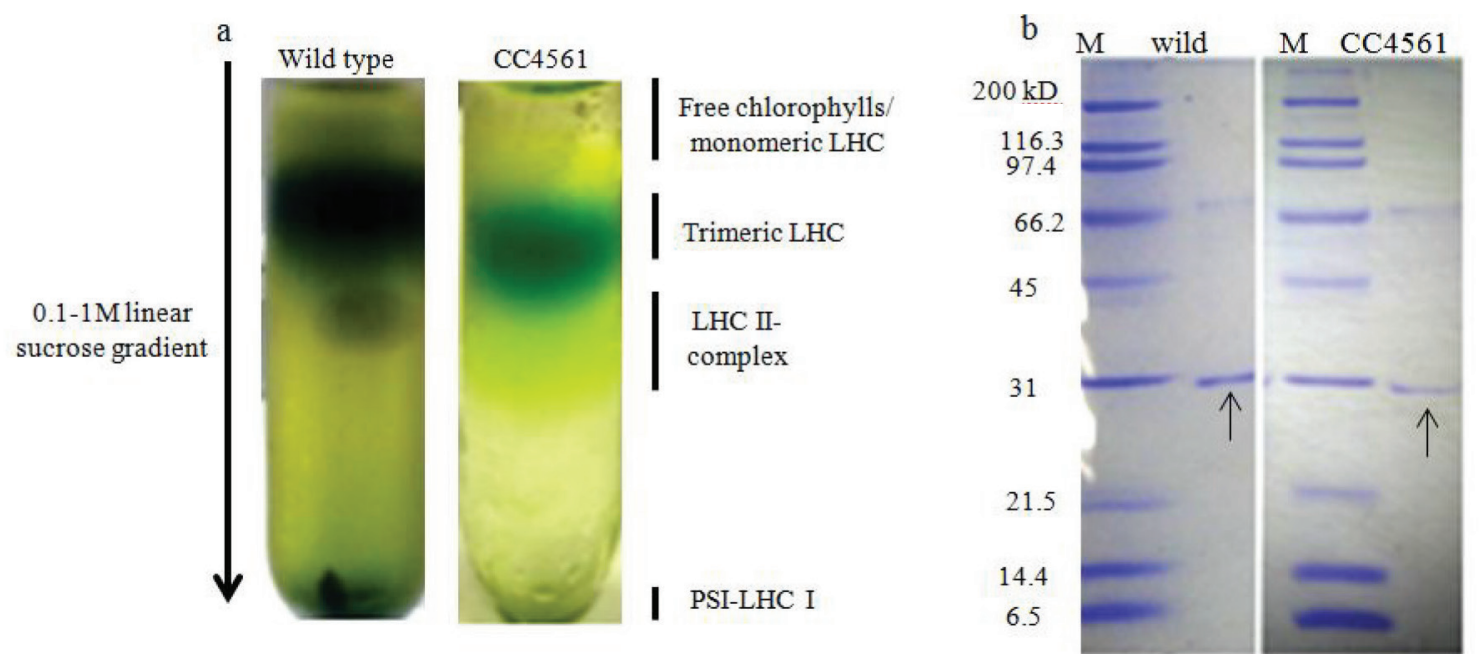

Figure 3: (a) Sucrose density gradient ultracentrifugation for solubilized thylakoid membranes showing top band of free chlorophylls and monomeric LHCs followed by green band of trimeric LHC, (b) Nondenaturing PAGE for the qualitative detection of LHC trimers showing $31 \mathrm{kD}$ trimeric LHCs indicated by arrows (figures right to left for wild type and truncated light harvesting antenna mutant CC4561 of C. reinhardtii). 


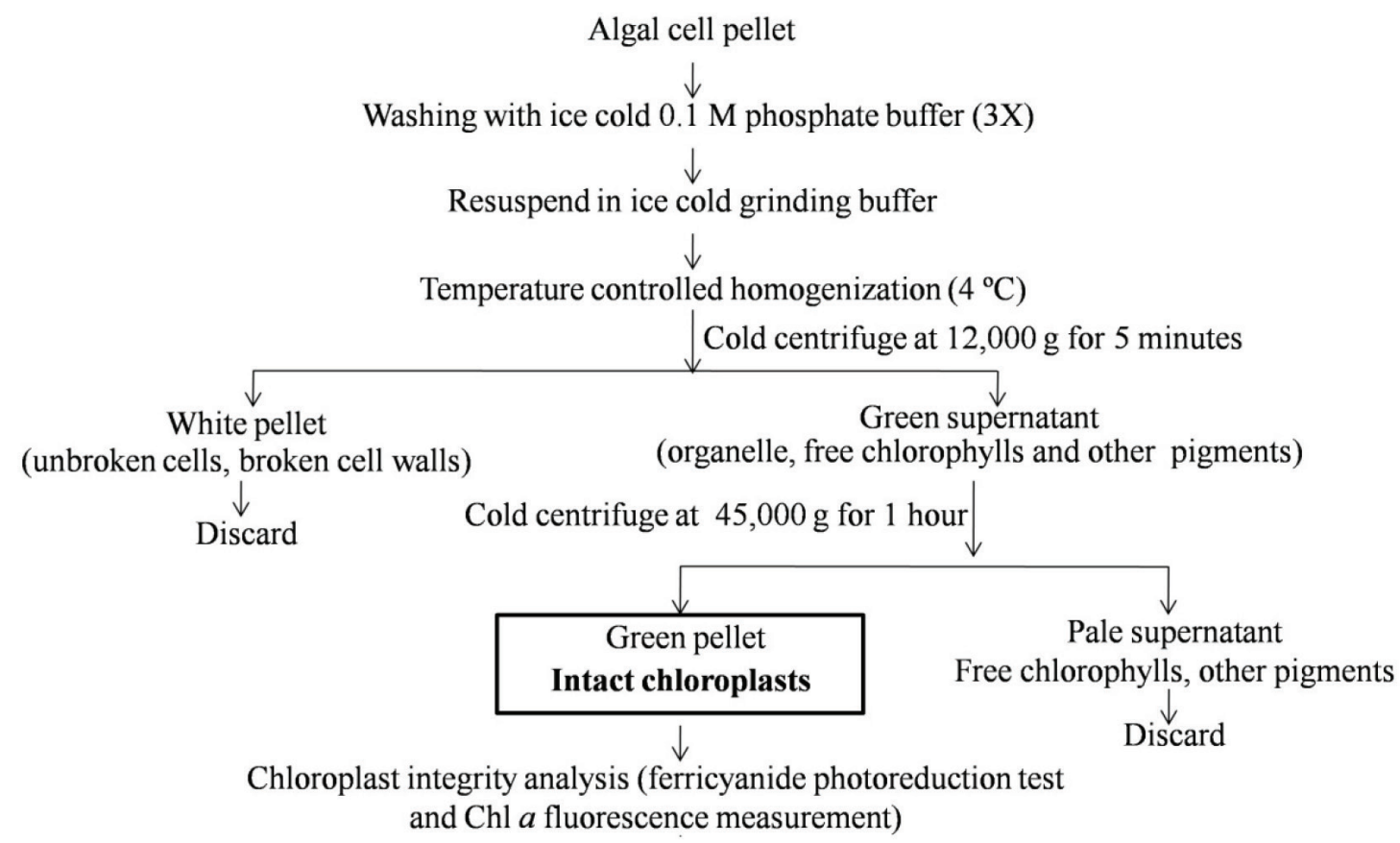

Figure 4: Flow chart depicting scheme for isolation, purification, and characterization of intact chloroplast from microalgal species.

The nondenaturing PAGE indicated the presence of $31 \mathrm{kD}$ LHC trimers in thylakoid solubilized fractions again indicating the applicability of the developed method for further downstream applications.

A detailed flow chart depicting an optimized protocol for the isolation of intact chloroplast is shown in Figure 4. Essential prerequisites for successful isolation of intact chloroplast and protein-pigment complex during homogenization are also mentioned separately (Supplementary material). The method can be applied to other algal species with variations of homogenization conditions. The current methodology has an advantage of scalability and finds its application in various studies, where structural and functional integrity of an organelle or other cellular components is essential.

\section{ACKNOWLEDGMENT}

This work was supported by the Department of Biotechnology, Ministry of Science and Technology, Government of India (No. BT/EB/ICT-Extension/2012). Ms. Smita Patil is thankful to DBT for the fellowship during the execution of the work.

\section{CONFLICT OF INTEREST}

The authors declare no competing interests.

\section{AUTHORS' CONTRIBUTIONS}

G.P. and A.M.L. conceived the idea. G.P. and S.P. discussed and planned the experiments. S.P. executed the experiments. G.P. and S.P. analyzed the results and wrote the manuscript. A.M.L. generated the funding for the work.

\section{FUNDING}

This work was supported by the Department of Biotechnology, Ministry of Science and Technology, Government of India (No. BT/EB/ICT-Extension/2012).

\section{REFERENCES}

1. McMillan JR, Watson IA, Ali M, Jaafar W. Evaluation and comparison of algal cell disruption methods: microwave, waterbath, blender, ultrasonic and laser treatment. Appl Ener 2013; 103:128-34.

2. Günerken E, D'Hondt E, Eppink HM, Garcia-Gonzalez L, Elst K, Wijffels RH. Cell disruption for microalgae biorefineries. Biotechnol Adv 2015; 33:243-60.

3. Owens TG, Wold ER. Light-harvesting function in the diatom Phaeodactylum tricornutum: Isolation and characterization of pigment-protein complexes. Plant Physiol 1986; 80:732-8.

4. Eriksson M, Gardestrom P, Samuelsson G. Isolation, purification, and characterization of mitochondria from Chlamydomonas reinhardtii. Plant Physiol 1995; 107:479-83.

5. Yoshida M, Yoshida Y, Fujiwara T, Misumi O, Kuroiwa H, Kuroiwa T. Proteomic comparison between interphase and metaphase of isolated chloroplasts of Cyanidioschyzon merolae (Cyanidiophyceae, Rhodophyta). Phycol Res 2011; 59:1-15.

6. Li C, Yang H, Xia X, Li Y, Chen L, Zhang M, Wang W. High efficient treatment of citric acid effluent by Chlorella vulgaris and potential biomass utilization. Bioresour Technol. 2013; 127:248-55.

7. Rathod JP, Prakash G, Vira C, Lali AM. Trehalose phosphate synthase overexpression in Parachlorella kessleri improves growth and photosynthetic performance under high light conditions. Prep Biochem Biotechnol 2016; 46:803-9.

8. Vira C, Prakash G, Rathod JP, Lali AM. Cloning, expression and purification of Chlamydomonas reinharditii CC-503 sedoheptulose1,7-bisphospjatase in Escherichia coli. Prep Biochem Biotechnol 2016; 46:810-4. 
9. Cazzaniga S, Dall'Osto L, Szaub J, Scibilia L, Ballottari M, Purton S, et al. Domestication of the green alga Chlorella sorokiniana: reduction of antenna size improves light-use efficiency in a photobioreactor. Biotechnol Biofuels 2014; 7:1.

10. Lilley R, Fitzgerald MP, Rienits KG, Walker DA. Criteria of intactness and the photosynthetic activity of spinach chloroplast preparations. New Phytologist. 1975; 75: 1-10.

11. Krause GH, Weis E. Chlorophyll fluorescence and photosynthesis: the basics. Annu Rev Plant Biol. 1991; 42:313-49.

12. Ikeuchi M, Yuasa, M, Inoue Y. Simple and discrete isolation of an $\mathrm{O} 2-$ evolving PS II reaction center complex retaining Mn and the extrinsic $33 \mathrm{kDa}$ protein. FEBS Lett 1985; 185:2:316-22.

13. Alvarej EV, Andreakis N, Leston LA, Pearson AG, Serrao AE, Procaccini G, et al. Genomic DNA isolation from green and brown algae (caulerpales and fucales) for microsatellite library construction. J Phycol 2006; 42:741-5.

14. Kirst H, Garcia-Cerdan JG, Zurbriggen A, Ruehle T, Melis A. Truncated photosystem chlorophyll antenna size in the green microalga Chlamydomonas reinhardtii upon deletion of the TLA3CpSRP43 gene. Plant Physiol. 2012; 160:2251-60.

15. Zheng H, Yi J, Gao Z. Disruption of Chlorella vulgaris cells for the release of biodiesel-producing lipids: a comparison of grinding, ultrasonication, bead milling, enzymatic lysis, and microwaves. Appl Biochem Biotech. 2011; 164:1215-24.

16. Mosier N, Wyman C, Dale B, Elander R, Lee YY, Holtzapple M, Ladisch M. Features of promising technologies for pretreatment of lignocellulosic biomass. Bioresour Technol. 2005; 96:673-86.

17. Jaenicke L, Kunhe W, Spessert R, Wahle U, Waffenschmidt S. Cell wall lytic enzymes (autolysins) of Chlamydomonas reinhardtii are (hydroxy) proline-specific proteases. Eur J Biochem. 1987; 170: 485-91.
18. Gerken HG, Donohoe B, Knoshaug EP. Enzymatic cell wall degradation of Chlorella vulgaris and other microalgae for biofuels production. Planta. 2012; 237:239-53.

19. Ramazanov A, Ramazanov Z. Isolation and characterization of a starchless mutant of Chlorella pyrenoidosa with a high growth rate, and high protein and polyunsaturated fatty acid content. Phycol Res 2006; 54:255-59.

20. Polle JE, Kanakagiri SD, Melis A. tla1, a DNA insertional transformant of the green alga Chlamydomonas reinhardtii with a truncated lightharvesting chlorophyll antenna size. Planta 2003; 217:49-59.

21. Sonoike K. Photoinhibition of photosystem I: its physiological significance in the chilling sensitivity of plants. Plant Cell Physiol 1996; 37:239-47.

22. Brestic M, Zivcak M. PSII fluorescence techniques for measurement of drought and high temperature stress signal in crop plants: protocols and applications. In: Gyana RR, Anath BD (eds.). Molecular stress physiology of plants. Springer, Berlin, Germany, pp 87-131, 2013.

\section{How to cite this article:}

Patil S, Lali AM, Prakash G. An efficient algae cell wall disruption methodology for recovery of intact chloroplasts from microalgae. J Appl Biol Biotech 2020;8(03):023-028. DOI: $10.7324 / J A B B .2020 .80305$ 